\title{
The heterogeneous clinical and pathological landscapes of metastatic Braf-mutated colorectal cancer
}

\author{
Giuseppe Nicolò Fanelli ${ }^{1 \dagger}$, Carlo Alberto Dal Pozzo ${ }^{1 \dagger}$, Ilaria Depetris ${ }^{2 \dagger}$, Marta Schirripa ${ }^{2}$, Stefano Brignola', \\ Paola Biason ${ }^{2}$, Mariangela Balistreri ${ }^{1}$, Luca Dal Santo ${ }^{1}$, Sara Lonardi ${ }^{2}$, Giada Munari ${ }^{1,2}$, Fotios Loupakis ${ }^{2 \dagger}$ \\ and Matteo Fassan ${ }^{1 *+}$ (i)
}

\begin{abstract}
Colorectal cancer (CRC) is a complex and molecularly heterogeneous disease representing one of the most frequent causes of cancer-related death worldwide. About 8-15\% of CRCs harbor a mutation in BRAF gene, a proto-oncogene involved in cell proliferation, differentiation and survival through the MAPK signaling cascade. The acquisition of BRAF mutation is an early event in the "serrated" CRC carcinogenetic pathway and is associated with specific and aggressive clinico-pathological and molecular features. Despite that the presence of BRAF mutation is a well-recognized negative prognostic biomarker in metastatic $C R C(\mathrm{mCRC})$, a great heterogeneity in survival outcome characterizes these patients, due to the complex, and still not completely fully elucidated, interactions between the clinical, genetic and epigenetic landscape of BRAF mutations. Because of the great aggressiveness of BRAF-mutated mCRCs, only $60 \%$ of patients can receive a second-line chemotherapy; so intensive combined and tailored first-line approach could be a potentially effective strategy, but to minimize the selective pressure of resistant clones and to reduce side effects, a better stratification of patients bearing BRAF mutations is needed.
\end{abstract}

Keywords: BRAF mutation, Colorectal cancer, Personalized medicine, Sequencing

\section{Background}

Colorectal cancer (CRC) is the fourth most common malignancy and the second most frequent cause of cancer-related death worldwide [1]. CRC is a complex and molecularly heterogeneous disease, characterized by different genomic landscapes [2, 3]. CRC phenotypic and molecular comprehensive characterization represents a key step, with diagnostic, prognostic and predictive value both in localized and in metastatic settings (mCRC) [4].

\footnotetext{
*Correspondence: matteo.fassan@gmail.com; matteo.fassan@unipd.it ${ }^{\dagger}$ Giuseppe Nicolò Fanelli, Carlo Alberto Dal Pozzo and Ilaria Depetris equal contribution as first authors

${ }^{\dagger}$ Fotios Loupakis and Matteo Fassan equal contribution as senior authors ${ }^{1}$ Surgical Pathology Unit, Department of Medicine (DIMED), University of Padua, via Gabelli 61, 35121 Padua, Italy

Full list of author information is available at the end of the article
}

Among the most frequent mutations with prognostic and predictive value, missense point mutations in $B R A F$ gene occur in about $8-15 \%$ of mCRC, being mutually exclusive with $R A S$ genes mutations [5].

$B R A F$ (v-raf murine sarcoma viral oncogene homolog $B$ ) encodes for a protein kinase acting through the MAP (mitogen-activated protein) kinase cascade, playing an important role in cell proliferation, differentiation and survival [6]. Given its pivotal location in many neoplastic-related dysregulated pathways, it easily explains its oncogenic role in many human malignancies, including melanoma, ovarian carcinoma, papillary thyroid carcinoma and CRC $[7,8]$. Of note, the oncogenic contribution of mutated $B R A F$ gene varies between cancer types, justifying significant differences in clinico-pathological 
features, prognostic impact and therapy response among various malignancies [9-13].

$B R A F$-mutated (BRAFmt) CRCs have specific clinicopathological and molecular features [14-18], identifying a distinct subset with aggressive phenotype and poor outcome (Fig. 1). Noteworthy, BRAFmt tumors are more frequent in elderly persons with scant performance status. By the pathological point of view, BRAFmt CRCs are characterized by more aggressive pathological features like high grade and peritoneal dissemination and they present in an advanced stage at the time of the initial diagnosis. Furthermore, BRAFmt mCRC patients usually develop an early resistance to standard and targetedtherapy, and only about an half of these patients can receive a second line chemotherapy, suggesting that more aggressive and individualized combined therapies may be effective in selected patients cohorts [7, 15, 19-24]. Nevertheless, $B R A F$ treatment-predictive value still remains a matter of debate.

A strong association between BRAF mutation and microsatellite instability (MSI) has been shown (46-75\%) [25-28]. This finding is consistent with the evidence that most BRAFmt CRCs develop via the "serrated pathway", often followed by a "CpG-island methylator phenotype" (CIMP) involved in promoter methylation and silencing of key onco-suppressor genes [29]. Moreover, MSI CRCs share some clinicopathological features with the $B R A F \mathrm{mt}$ ones [27]. By contrast, a small amount of CRCs harbor a $B R A F$ mutation but remain microsatellite-stable (MSS), resulting in a worse prognosis than BRAFmt/MSI cancers [30, 31]; however, molecular characterization and predictive value of this particular subgroup has not yet been fully clarified. Because of the above mentioned prognostic and predictive implications, the molecular profiling of RAS (KRAS and NRAS) and BRAF genes and the assessment of Mismatch Repair (MMR)/MSI status has now been added into the main CRC diagnostic and therapeutic algorithms [32].

Of note, many studies have demonstrated that the $B R A F$ negative prognostic impact is often independent of the other considered clinico-pathological features [33]. This could be related to several factors: different $B R A F$ mutations have different prognostic value [34]; CRC intratumor heterogeneity and the complex interactions with other molecular alterations can influence the therapeutic response; $B R A F$ mutation in CRC is difficult to target and several resistance mechanisms have been discovered, but some of them still remain unknown; tumor stage can influence the prognostic value of $B R A F$ mutations.

Despite remarkable advances in CRC molecular classification have been made, the abovementioned aspects underline a still unsatisfied need: a reliable prognostic and predictive stratification for CRC patients that harbor a $B R A F$ mutation. All of these aspects will be fully analyzed in the present review, in order to provide a comprehensive overview on current clinico-pathological, prognostic and predictive implications of $B R A F$ mutation in CRC.
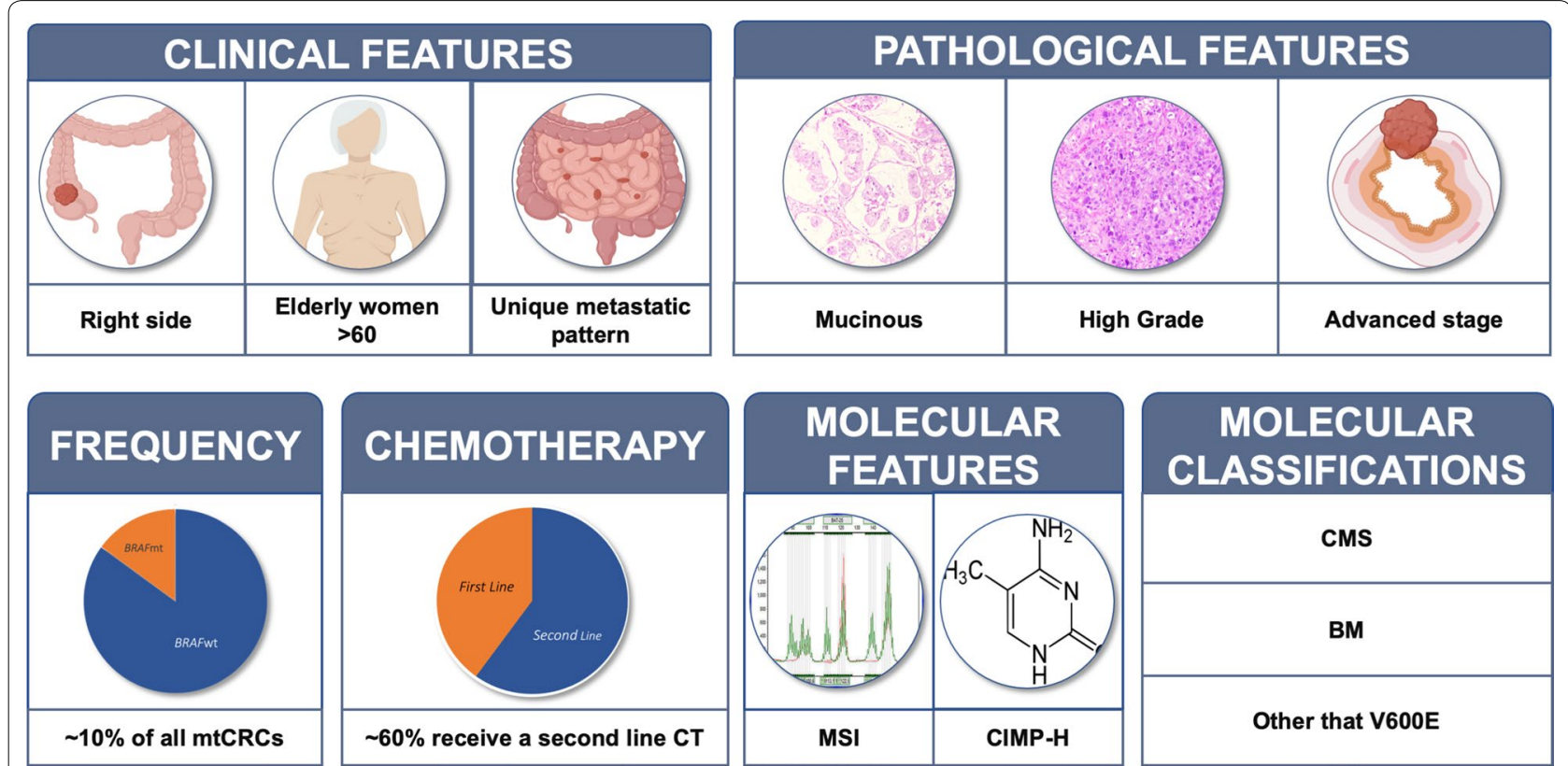

Fig. 1 Clinico-pathological features associated to BRAF-mutated colorectal cancers 


\section{$B R A F$ gene and its pathway}

$B R A F$ is a proto-oncogene that encodes for a cytoplasmic serine/threonine kinase (STK), an essential component of the RAS/RAF/MEK/ERK signaling cascade [35]. Physiologically, extracellular soluble factors like EGF (Epidermal Growth Factor) bind and activate EGFR (Epidermal Growth Factor Receptor), a Receptor tyrosine kinases (RTK). Through the recruitment of two adaptor proteins (SOS and GRB2) EGFR activation allows KRAS to release GDP and to bind GTP. After some conformational changes, KRAS recruits and binds the cytosolic BRAF, which forms an active homo- or hetero-dimer with other component of the RAF family proteins. This homo/hetero-dimer phosphorylates and activates MEK kinases (MEK1 and MEK2) and, finally ERK, which translocates in the nucleus, stimulating transcription factors involved in proliferation, differentiation, cell motility, apoptosis (regulating BCL-2) and survival (through the HIPPO pathway) $[5,35]$.

\section{BRAF mutations and CRC clinico-pathological features}

Different $B R A F$ point mutations can affect the encoded protein function in many ways; most of them cluster to the conserved P loop and DFG motif of the kinase, destabilizing the inactive protein structure and thereby promoting an active conformation $[34,36]$.

The most common BRAF mutation (90\%), in CRC as well in others malignancies, is a CTG $\rightarrow$ CAG transversion at residue 1799 (T1799A), leading to an amino acidic substitution from valine to glutamic acid at codon 600 (p.V600E) in the exon 15 ( $\left.{ }^{\mathrm{V} 600 \mathrm{E}} B R A F\right)$. This results in a constitutive-active kinase, 500-fold more active than BRAFwt [36]. Among all malignancies, V600E mutation occurs in $8-10 \%$ of all cancers (melanoma $66 \%$, papillary thyroid cancer $53 \%$, serous ovarian cancer $30 \%$ and $8-15 \%$ of sporadic CRCs) and it is often associated with poor prognosis [37, 38].

${ }^{\mathrm{V} 600 \mathrm{E}} B R A F$ mutation prevalence in CRCs is different among ethnic group (Asian population shows a lower frequency compared with Caucasian population) [39] and tumor-stage $\left({ }^{\mathrm{V} 600 \mathrm{E}} B R A F\right.$ mutation frequency is significantly higher in stage II/III than in stage IV) [40]. However, its prognostic value in early disease is still controversial and should be further investigated [40, 41].

mCRCs harboring ${ }^{\mathrm{V} 600 \mathrm{E}} B R A F$ mutations have distinct clinico-pathological features compared to $B R A F \mathrm{wt}$ ones, outlining a unique (and often easily recognizable) subgroup [14, 42]: clinically, $B R A F \mathrm{mt}$ mCRCs arise in older patient ( $>60$ years old); this is in line with the evidence that BRAF mutations are an acquired genetic event, occurring mainly in sporadic CRCs and are unlikely to be common in younger patients [42]. BRAFmt mCRCs are prevalent in the female gender, regardless of the MSI status [42]; proximal colon is the preferential location, suggesting that the genomic alterations in proximal and distal colonic mucosa produce different CRC phenotypes [42]. Moreover, BRAFmt mCRCs present a unique metastatic pattern, showing high rates of peritoneal metastases, distant lymph node metastases [15, 27, 43-45] and low rates of lung metastases $[15,27]$. Instead, no significant differences have been seen in liver or brain metastases rates [27]. Finally, ${ }^{\mathrm{V} 600 \mathrm{E}} B R A F \mathrm{mCRC}$ patients usually have worse performance status (PS 1-2 using Eastern Cooperative Oncology Group scale) at first diagnosis [44, 45].

${ }^{\mathrm{V} 600 \mathrm{E}}$ BRAF CRCs have histological hallmarks that are widely reported in literature, such as mucinous features, serrated architecture, poor differentiation and high stage at diagnosis [14, 16, 23, 25, 42-46]. Other less peculiar features are a higher frequency of tumor budding and signet ring cells, infiltrative pattern of invasion with an increased risk of lympho-vascular but not perineural invasion, different grade of Tumor Infiltrating lymphocytes (TILs) and of peritumoral lymphoid reactions (Crohn-like) [16].

In addition, Chen et al. [14] explored the association between BRAF mutations and behavioral risk factors for CRC development. Despite these analyses were affected by the lack of data, is apparently excluded an association between ${ }^{\mathrm{V} 600 \mathrm{E}} B R A F$ mutation and smoking or dietary habits, while alcohol intake seemed to act as a protection factor against the same mutation.

\section{BRAF mutations and CRC carcinogenesis}

Several molecular, morphologic and clinico-pathologic features have been studied to classify CRC and its carcinogenetic pathways, in order to better stratify patients and guide their therapeutic management. Three genomic pathways essentially drive CRC carcinogenesis: (i) the chromosomal instability (CIN) or aneuploidy pathway, which causes numerous changes in chromosomal copy number and structure; (ii) the microsatellite instability (MSI pathway, with loss of MMR function; and (iii) the "CpG island methylator phenotype" (CIMP) characterized by epigenetic instability due to methylation and silencing of critical tumor suppressor genes [2, 15, 4749], a great overlap exists between the last two pathways.

Phenotypically, CRC pathogenesis has been described as a multistep process and two alternative pathways lead to sporadic invasive cancer: (i) the "conventional pathway" (tubular and tubulovillous adenoma $\rightarrow$ carcinoma) and (ii) the "serrated pathway" (microvesicular and goblet cell hyperplastic polyp $\rightarrow$ sessile serrated and traditional serrated adenoma $\rightarrow$ carcinoma). The three abovementioned genomic instability pathways are differentially 
involved in these two different progression models $[15$, 50].

The "conventional" pathway $(70-80 \%$ of sporadic CRCs), is linked to CIN and is characterized by an early $A P C$ truncating mutation and subsequent alterations in SMAD4 and TP53 genes for the tubular adenoma (CRC $B R A F \mathrm{wt} / K R A S \mathrm{wt} / \mathrm{MSS}$ ) and also in $K R A S$ gene for tubulovillous adenoma (CRC BRAFwt/KRASmt/MSS) [5, 51].

The "serrated" pathway (20-30\% of sporadic CRCs) is related to MSI and CIMP $[5,51]$ and could be split in two routes according to the precursor lesions and mutational status of $B R A F$ and $K R A S$ genes. The former gene mutations occur frequently in microvesicular hyperplastic polyp (MVHP) and in sessile serrated lesion (SSL), are linked to "CIMP-High" phenotype and could be associated with either MSS or MSI status (CRC: BRAFmt/ CIMP-H/MSI or BRAFmt/CIMP-H/MSS); whereas the latter have a higher incidence in goblet cell hyperplastic polyp (GCHP) and in traditional serrated adenoma (TSA), is linked to "CIMP-Low" phenotype and have a MSS status (CRC KRASmt/CIMP-L/MSS) [52].

Hyperplastic polyps (HPs) represent more than $75 \%$ of the serrated polyps [35], they can be endoscopically recognized as flat or sessile polyps, pale in color, generally $<5 \mathrm{~mm}$, and usually located in the distal colon (85-90\%). However, only two HPs subgroups (MVHPs and GCHPs) might rarely acquire transforming and progression capacity $[53,54]$.

MVHPs are typically located in the proximal colon and are histologically composed of funnel-shaped crypts with serrations limited to upper two-thirds, the proliferation zone is located uniformly in the basal portion of crypts and cytologically have small basally located nuclei without dysplasia. Whether SSL arise de novo or from MVHP still remains debated and the molecular driver of this transition is unclear. However, MVHP and SSL have overlapping molecular alterations, both harbor an activating BRAF mutation, but only $10 \%$ of MVHPs have CIMP-High phenotype versus $40-50 \%$ of SSLs [51].

GCHPs could be located in proximal or distal colon and are histologically characterized by elongated crypts that resemble enlarged normal crypts with little/no serrations composed by cells with small and basally located nuclei without dysplastic hallmarks and the proliferation zone located at the cryptal basis. A GCHP can sometimes be found on the 'shoulder' area of TSA, and KRAS mutation is present in $43-54 \%$ of GHCPs suggesting that KRAS mutated TSAs may arise from this subgroup of HPs [51].

SSLs (20-25\% of the serrated polyps) [52] are the most relevant serrated polyps, since they are the precursors of the largest proportion of CRCs developed through the serrated pathway. Macroscopically, they appear as flat or slightly elevated areas of mucosa, often located in the proximal colon and generally sized $>5 \mathrm{~mm}$ with a yellow mucous cap that often make the endoscopic diagnosis easier [54, 55]. The histologic hallmarks of SSL are the serrations extended into the crypt base that are horizontally enlarged along the muscularis mucosae, creating characteristic asymmetric structures $(\mathrm{T}$ - or inverted L-shaped) [51]. Of note, only $2-5 \%$ of SSLs $(<0.5 \%$ of serrated polyps) progress towards invasive CRCs and the hallmark of this progression potential is the dysplasia [56-58] characterized by architectural changes (crowded and elongated crypts with increased branching complexity, cribriforming, and villous architecture) and cytological atypia (from subtle hypermucinous changes to overt dysplastic changes) [59]. The molecular landscape of SSLs is characterized by wild type KRAS, mutated $B R A F$, CIMP-H phenotype (acquired in early phase) with methylated MLH1 which result in MSI or methylated $M G M T$ with MSS status, WNT pathway activation and in a minority of cases p16 silencing and TP53 mutation (acquired in late phase with dysplasia) [60].

Only $5 \%$ of serrated polyps are TSAs. They range from 9 to $14 \mathrm{~mm}$ in maximum dimension, endoscopically have a "pinecone-like" appearance and a proximal or distal location; the three histological hallmarks are: the slit-like serrations, the ectopic crypt foci and the eosinophilic cells with stratified elongated nuclei [51, 52, 61]. TSAs have an unquestionably malignant potential, but the absence of clear cytological atypia, infrequent or absent mitoses, low Ki-67 proliferation index, $\beta$-catenin and p53 negativity, and retention of p16 staining, suggest TSAs are not intrinsically dysplastic, but a superimposed dysplasia (conventional and/or serrated) can develops during progression [61]. The molecular features are quite peculiar, indeed TSAs presenting KRAS mutation (5070\%) are left-sided, have CIMP-L phenotype and when they acquire high grade dysplasia they also present TP53 mutations and WNT pathway activation, giving rise to $K R A S \mathrm{mt} / B R A F \mathrm{wt} / \mathrm{MSS}$ CRCs; while TSAs with BRAF mutations (20-40\%) are right- or left-sided, have CIMP-L (or intermediate) phenotype and in the subsequent phase acquire TP53 mutation and WNT activation leading to KRASwt/BRAFmt/MSS CRCs [54]. Thus, TSA could be the precursor of the this latter rare and aggressive CRC molecular subtype [61].

Of note, the serrated polyps described above, are not mutually exclusive: they can co-exist in the same patient or even in the same polyp; this could be related to polyps that switch phenotype as they accumulate genetic events, evolving from a kind of lesion to another characterized by greater progression potential or could be the result of different genomic pathways that create a collision lesion $[61,62]$. 
Thanks to all these morphological and molecular data, it is straightforward to understand how BRAF mutation is an early event in CRC carcinogenesis. In fact, it is present even in the $63 \%$ of "serrated aberrant crypt foci", the earliest premalignant serrated lesion [63]. Furthermore, testing for ${ }^{\mathrm{V} 600 \mathrm{E}} B R A F$ in primary CRCs and matched metastases, suggests a good mutational status concordance between primary and secondary lesions and tumors lacking ${ }^{\mathrm{V} 600 \mathrm{E}} B R A F$ do not acquire this mutation in their metastases [64]. However, BRAF mutation alone is not sufficient for malignant transformation [65] as demonstrated by recent studies that point out the pivotal role of WNT signaling hyperactivation in the "serrated pathway" [66] and suggest how mutant $B R A F$, phosphorylating the transcriptional co-repressor MAFG, via the BRAFMEK-ERK axis, induces CpG-islands hypermethylation [5, 67]; this could be the molecular confirmation of the link between BRAF mutation and CIMP-H/MSI status in CRC [68]. These new insights could explain the apparent change of the $B R A F$ mutation clinical value during the natural history of CRC.

\section{BRAF mutations and new CRC molecular classifications}

Recently, the CRC Subtype Consortium (CRCSC), analyzing and merging different subtyping algorithms based on several gene expression data sets, identified 4 CRC consensus molecular subtypes: CMS1 (14\% MSI immune: hypermutated, MSI, with a strong immune activation), CMS2 (37\% canonical: epithelial, marked WNT and MYC signaling activation), CMS3 (13\% metabolic: epithelial and metabolic dysregulation), and CMS4 (23\% mesenchymal: TGF- $\beta$ activation, stromal invasion and angiogenesis). About $45 \%$ of CMS1 group, less than $10 \%$ of CMS3/CMS4 and less than 5\% of CMS2 groups harbor a $B R A F$ mutation, in line with the well-known association between this event and MSI. Of note, our group has recently demonstrated that CMS subgrouping is significantly associated to a prognostic stratification in a large series of Italian BRAFmt mtCRCs [69].

However, this classification is not able to explain the high heterogeneous targeted-therapy response in the ${ }^{\mathrm{V} 600 \mathrm{E}}$ BRAF CRCs subgroup. Hence, according to gene expression profiles, Barras et al. [70] distinguished two subtypes of ${ }^{\mathrm{V} 600 \mathrm{E}} B R A F$ mutants: BM1 and BM2.

BM1 (one-third of all BRAFmt CRCs) is characterized by KRAS/AKT pathway activation, mTOR/4EBP1 deregulation and EMT enhancing [70]. Whereas, in BM2 group (two-thirds of BRAFmt CRCs) is present a cellcycle and cycle checkpoints-related events deregulation [70].

Intriguingly, several molecular differences have been observed between BM1 and BM2 groups. BM1 group displays a stronger immune profile (IL2/STAT5, IL6/JAK/
STAT3 pathways activation, TNF- $\alpha$ signaling via NF-kB, and allograft rejection) and an enrichment in angiogenesis and TGF- $\beta$-mediated processes; while BM2 group is enriched in metabolic processes and displays high CDK1 and low cyclin-D1 levels [70].

Although BM1 subtype seems to results in a poorer prognosis compared to BM2 subtype, MSI status remain the dominant prognostic factor; in fact, BM classification is independent of MSI status, methylation patterns, PI3K mutation, gender and sidedness [70].

Most BM1 and BM2 patients (70\%) were classified into CMS1, whereas only a few were found in CMS2 (2\%), CMS3 (5\%), and CMS4 (17\%). Interestingly, all CMS4 $B R A F$ mutants are classified as BM1, whereas CMS1 BRAF mutants are distributed into both BM1 and BM2, demonstrating that BM subgroups can refine CMS classification, capturing additional transcriptomics variations within the $B R A F$ mutants of the CMS1 group [70].

Even if V600 is the most frequent BRAF mutation in CRCs, other non-V600 mutations have been identified by novel and more accurate molecular techniques [36]. Performing functional studies on non-colorectal preclinical models, Yao et al. [71, 72] classified the entire spectrum of $B R A F$-activating mutations according their RAS dependency for signaling and whether they act as a monomer or dimer. Three classes have been identified: class 1 includes the V600 mutations and BRAF protein acts as constitutively active monomer; class 2 consists of kinase active mutations in codons 464, 469, 597 or 601 and BRAF acts as constitutively active dimer; for both class (1 and 2) kinase activity is RAS-independent [71]; class 3 mutations affect codons $287,459,466,467,469,581,594,595$ or 596, and BRAF can act as a dimer but has impaired or no kinase activity, so signaling is RAS-depend and remain sensitive to ERK-mediated inhibiting feedback $[35,72]$.

Non-V600 BRAF mutations are present in less than $2 \%$ of CRCs and their prognostic and predictive value is not yet well characterized. Conversely to other kinaseactivating mutations, class 3 comprises DFG inactivating mutations that increase the heterodimerization of BRAF with wild-type CRAF, inducing an indirect and only modest activation of MAPK pathway, demonstrated by MEK and ERK phosphorylation [45]. Although these mutations confer an impaired kinase activity, they retain an oncogenic potential that could be explained with the co-expression of other molecular alterations; in fact, kinase-dead BRAF mutants coexist and synergize with $R A S / E G F R$ gain-of-function mutations, while these genomic events are mutually exclusive in other subgroups of CRCs [73].

Hence, CRCs bearing non-V600 BRAF mutations constitute a distinct clinico-pathological subset, different 
from other $B R A F$ mutations classes; indeed, class 2 and class 3 CRCs usually are non-mucinous, MSS, arise on the left side of younger male patients, have no peritoneal spread, lower grade at presentation and are related to a more favorable overall survival (OS) rates compared to both ${ }^{\mathrm{V} 600 \mathrm{E}} B R A F$ mutants and wild-type CRCs [23, 34, 74].

\section{BRAF mutations and MMR status in CRC}

Microsatellites are repetitive DNA sequences repeated within genome, in both coding and noncoding regions. MSI is a condition of genetic hyper mutability resulting from defective DNA MMR machinery. It is characterized by clustering of mutations in microsatellites, typically consisting of repeat length alterations. The presence of MSI represents the phenotypic evidence of MMR deregulation [75].

Approximately 15\% of CRCs display MSI due to either a germline mutation in MMR genes (genetic MSI, called Hereditary Non-Polyposis Colorectal Cancer or Lynch syndrome, $3 \%$ ) or a somatic inactivation of one gene of the same group, most commonly through the hypermethylation of $M L H 1$ promoter region (sporadic MSI, 12\%) [76]. MSI prevalence in early stage disease (stage II and III) is about $15 \%$ and is related to better OS and disease free survival (DFS) and lower metastatic rate; whereas, there are only limited and inconsistent data regarding MSI prognostic implications in higher stage disease (stage IV) also due to its less prevalence (3-5\% of $\mathrm{mCRCs})[27,77]$. The predictive role of MSI in early stage is still matter of debate: although with conflicting results, a large amount of preclinical and clinical evidences suggests a possible resistance to fluoropyrimides in these CRC patients predicting a worse response to adjuvant chemotherapy $(\mathrm{CT})$ with fluorouracil-based regimens $[78,79]$.

The somatic inactivation of MMR genes is strongly associated with ${ }^{\mathrm{V} 600 \mathrm{E}} B R A F$ mutation $(60 \%)$, which is virtually absent in Lynch syndrome [80, 81]. Hence, somatic $B R A F$ mutation testing has been included into the Lynch syndrome screening algorithm [76, 82-86]. The prognostic and predictive value of coexisting $B R A F$ mutation and MSI is still matter of debate.

MSI CRCs share several clinico-pathological features with the BRAFmt ones: old age, female sex, right-side, large size, advanced pathologic $\mathrm{T}$ stage at diagnosis, mucinous features, poor differentiation, high grade TILs and peritumoral lymphoid reactions (Crohn-like) [15]. Molecular basis of the close relationship between MSI, high grade histology and TILs relies on MMR deficiency that leads to an elevated mutational burden, and wide expression of neoantigens [46]. However, effects of $B R A F$ mutational status on immune response remain unclear. In fact, while there are evidences that TILs (especially CD8+ T-cells) are associated with MSI/BRAFwt CRCs (Lynch syndrome) [87, 88], this relationship remains unclear in BRAFmt CRCs. On the contrary, the presence of a marked peritumoral lymphoid reaction is often present in BRAFmt CRCs (regardless to MSI status), but its prognostic value has not yet been fully elucidated; Zlobec et al. [89] suggest that peritumoral-only inflammation and relative lack of TILs might explain part of the poor prognosis of patients with BRAFmt CRCs.

It is also possible to recognize some immunohistochemical features related to MMR status and BRAF mutations, in particular: a reduction in CDX2 staining, related to adverse prognosis, is present both in $B R A F \mathrm{mt} / \mathrm{MSI}$ and BRAFmt/MSS CRCs [90, 91]; CK20 expression is preserved in $B R A F \mathrm{mt} / \mathrm{MSS}$ [30] as in $B R A F \mathrm{wt}$, but lost in BRAFmt/MSI CRCs CRCs [30, 90, 91]; CK7 is only minimally expressed in CRCs [92] but is frequently upregulated in BRAFmt/MSS CRCs [30] interestingly in tumor budding regions [93].

The most common and therefore deeply studied $B R A F \mathrm{mt}$ CRC subtype is that one catheterized by MSI, but unfrequently $B R A F \mathrm{mt}$ CRCs retain MSS; this unique subtype is related to poorer outcomes compared to $B R A F \mathrm{mt} / \mathrm{MSI}$ CRCs regardless the stage [25, 28, 82-84], with similar rates of KRASmt/MSS CRCs (both in stage III and in stage IV, even after complete liver metastasectomy) $[94,95]$. BRAFmt/MSS CRC shares some clinical features with $B R A F \mathrm{mt} / \mathrm{MSI}$ one, like the proximal colon location, but does not have a different gender distribution and usually arises in younger patients. Histologically, like $B R A F \mathrm{mt} / \mathrm{MSI} \mathrm{CRC}$, is mucin-producing and poorly differentiated $[31,96]$, but presents more aggressive morphological features such as frequent tumor budding, lack of TILs, frequent lymphatic, perineural, and vascular invasion and increased lymph node metastases compared to both $B R A F \mathrm{mt} / \mathrm{MSI}$ and BRAFwt CRCs [30, 31]. Molecularly, BRAFmt/MSS CRCs have multiple genetic aberrations associated with both "serrated" and "conventional" pathways. Indeed, often displaying TP53 mutation, correlated with "conventional" pathway and advanced stage but uncommon in MSI CRCs [82-84]; have a comparably high rate of CIN as BRAFwt CRCs, though with different patterns ("focal" vs "whole chromosome arms") [82, 83] indicating the prominent CIN contribution to the progression and poor outcomes [83]. Conversely, BRAFmt/MSS CRCs often present hypermethylated genes (at 60\%), an infrequent event in "conventional" pathway CRCs $(3 \%)$ [82, 83], demonstrating that CIMP is prevalent in all BRAFmt CRCs, but at a higher frequency in MSI (70-80\%) than MSS (60\%) cancers $[82,84]$. 


\section{Prognostic impact of BRAF mutations in CRC}

Despite new chemotherapeutic regimens and targeted drugs have been approved, patients with $B R A F \mathrm{mt}$ CRC still have lower response rates to conventional therapies and poorer OS rates regardless of their stage at diagnosis (5-years OS $47.5 \%$ vs. 60.7\%) [15]. However, is important to consider the clinical and molecular context in which $B R A F$ mutations occur and in particular the MMR status at diagnosis.

Indeed, according to several independent studies, patients with ${ }^{{ }^{6} 600 \mathrm{E}} B R A F$ CRC have significantly poorer OS compared to patients with $B R A F \mathrm{wt}$ CRC, regardless MMR status and stage, but only in a univariate analysis and not in multivariate analysis, suggesting the presence of confounding factors [28, 50, 94, 97]. Nevertheless, Samowitz et al. [26] postulated that the negative prognostic value of $B R A F$ mutational status is subject to MMR status, regardless of stage, showing that in microsatellitelow (MSI-L)/MSS CRCs BRAF mutation was prognostic for poor OS while in MSI-H CRCs BRAF mutational status seems to have no significant effect on 5-year OS; similar findings has been reported also by Roth and colleagues [25] for early stage disease (stage II and III). Conversely, other authors reported that $B R A F$ mutation with MSI, in early CRC stage, may represent a positive prognostic marker, associated with a lower risk of dissemination [40].

Whereas to date, BRAF mutation remains the only oncogenic mutation that predicts poor prognosis in mCRC $[15,50]$. Tran et al. [27] reported a strong association between MSI and BRAF mutation and demonstrated poorer OS rates in MSI mCRCs suggesting that, unlike in early stage disease, MSI could represent a negative prognostic factor in advanced disease, although this is driven by its association with $B R A F$ mutations.

Even though we are in the in the era of molecular characterization, sometimes $B R A F$ testing is not available or reimbursed, but given its great negative prognostic value, in mCRC patients, a simple nomogram to predict ${ }^{\mathrm{V} 600 \mathrm{E}} B R A F$ mutation in RASwt population has been developed, using gender, primary tumor location (rightsided vs left sided) and histology (mucinous vs non mucinous). mCRC patients with the highest score (right-sided primary, female and mucinous) had a $81 \%$ chance to bear ${ }^{\mathrm{V} 600 \mathrm{E}}$ BRAF mutation [44].

However, the outcomes of patients with BRAFmt $\mathrm{mCRC}$, still remain quite heterogeneous [33]. The molecular and clinical basis of these differences could be related to different $B R A F$ mutation types, MMR status and to other several genomic events occurring in CRC pathogenesis [34, 70-72]. Indeed, non-V600E BRAFmt mCRCs remain a unique subset with better OS compared with both with $B R A F \mathrm{wt}$ and with ${ }^{\mathrm{V} 600 \mathrm{E}}$ BRAFmt ones [14, 23].
This complex interaction could also validate some $B R A F \mathrm{mt}$ mCRCs clinical aspect related to worse prognosis such as the peculiar metastatic spread pattern (peritoneal dissemination and increased number of metastasis) [98].

Therefore, since the remarkable prognostic difference between MSS/BRAFmt and MSI/BRAFmt CRCs, even in metastatic settings, molecular subtyping according BRAF mutational status alone is an insufficient prognostic index and the assessment of MMR status should always be performed [15]. In addition, the inclusion of other clinical and laboratory criteria could be useful to better prognostically stratify $B R A F$ mutant patients as recently demonstrated by Loupakis et al. $[99,100]$; items included in this prognostic score are: performance status, CA19.9, LDH, neutrophils/lymphocytes ratio, grading, liver/lung/nodal involvement. Combining these variables authors built both a "complete" prognostic score, and a "simplified" one (excluding laboratory features). Although further validations are needed, this prognostic scoring systems seems to be sufficient to stratify patients in 3 subgroups (low, intermediate and high risk) with significantly different outcomes.

\section{Predictive impact of BRAF mutations in CRC and new therapeutic approaches}

If the prognostic value of $B R A F$ mutations in CRCs has been widely demonstrated, their predictive value is a question still to be answered.

mCRC patients harboring ${ }^{\mathrm{V} 600 \mathrm{E}} B R A F$ mutation have worse OS, mostly in the subgroup treated with conventional CT [50]. These data are consistent with several studies where ${ }^{\mathrm{V} 600 \mathrm{E}}$ BRAFmut patients showed significantly poorer PFS and post-progression survival (P-PS) during first-line CT treatment [101, 102]. Conversely, other studies, even with some limitations, reported that BRAF mutational status has a modest or no impact on PFS of first-line CT, but median PFS dramatically declines for $B R A F \mathrm{mt}$ patients during second and thirdline CT treatment $[33,46,50]$. The poor PFS of $B R A F \mathrm{mt}$ patients could be related to the early development of resistance mechanisms, more rapidly than in $B R A F \mathrm{wt}$ patients [15].

Mutations in the RAS genes (KRAS and NRAS), the upstream effector of BRAF in RAS-RAF-MAPK and PI3K-AKT-mTOR signalling pathway, are well-recognized biomarkers of resistance to anti-EGFR monoclonal antibodies (MoAbs) [103-107] conversely, the predictive role of $B R A F$ mutations in patients receiving targetedtherapies remains uncertain. Several independent studies and metanalysis investigated the predictive role of $B R A F$ mutations for anti-EGFR targeted treatments, observing that, like $R A S, B R A F$ mutations could predict resistance 
to anti-EGFR therapies $[46,106,108-110]$; on the contrary, a metanalysis including 7 randomized trials evaluating the BRAF mutations effect on anti-EGFR treatment, reported that there are insufficient evidences to definitively confirm that $B R A F \mathrm{mt}$ patients do not benefit from anti-EGFR therapy [111]. These ambiguous conclusions could depend on the small number of patients enrolled in the studies and on the consequent impossibility to characterize the heterogeneity among the population of $B R A F$ mutated patients.

Due to the aggressiveness of $B R A F \mathrm{mt} \mathrm{mCRC}$, only $60 \%$ of patients can receive a second-line CT treatment [20, 33]. Hence, intensive and combined first-line approach with conventional $\mathrm{CT}$ and targeted therapies could be a potentially effective strategy, as demonstrated by FOLFOXIRI plus bevacizumab regimen, which demonstrated an improved response rates compared to FOLFIRI in late-stage BRAFmt CRC [112], and increased PFS and OS $[23,24,113,114]$. However, this intensive approach could be limited by increased toxicity in these patients, who typically have a reduced performance status at diagnosis $[20,24,112,115,116]$.

Several targeted inhibitors against BRAF mutations or other key components of MAPK pathway are emerging, but unfortunately, differently from other cancers, $B R A F \mathrm{mt} \mathrm{mCRCs}$ resistance to single targeted-drug regimens is broadly attested in clinical practice. In melanoma, sorafenib, the first tyrosine kinase inhibitor (TKI) of RAF-kinases, achieved only scant clinical effects due to its greater affinity for other kinases besides BRAF [117]; subsequently a TKI able to target ${ }^{\mathrm{V} 600 \mathrm{E}} B R A F$ mutation was developed, vemurafenib, and in phase III trial demonstrated improved rates of OS and PFS compared to standard CT (dacarbazine) in patients with previously untreated melanoma with the BRAF V600E mutation [118]. In BRAFmt mCRC no similar results were achieved using TKI against BRAF [33, 35, 119]. Similar assumptions have been made for dabrafenib, another strong and selective BRAF TKI, whose clinical effect as single agent in metastatic melanoma is limited due to the rapid acquisition of resistance mechanisms [117]. To explain unresponsiveness of $\mathrm{mCRC}$ to BRAF inhibition, several resistance mechanisms have been identified: firstly, BRAF inhibition can induce a feedback activation of EGFR, which supports cellular proliferation; interestingly a difference in EGFR expression degree between melanoma and $\mathrm{mCRC}$ cells has been observed, which could partially explain the difference in clinical response to BRAF inhibition [119]. Moreover, BRAF inhibition stimulates an ERK-dependent activating feedback on EGFR, with a MAPK pathway reactivation through CRAF and the hetero-dimerization between CRAF and BRAF, making monomeric BRAF-inhibitors ineffective [71, 120]. Other mechanisms of acquired resistance include: ERK-mediated gain-of-function, MEK1 mutations, $B R A F$ amplification and KRAS alterations [19, 121]. Finally, PI3K pathway crosstalk-activation through KRAS, as well as mutations in PIK3CA and PTEN, confers cancer cells resistance to MAPK inhibition [122].

Hence, it is necessary to introduce a broader combinatorial therapy, using targeted drugs acting on multiple critical biological processes for the neoplastic cells, like the combination of BRAF-/MEK-/ERK-inhibitors, with anti-EGFR MoAbs and/or standard CT agents. Considering the rationale for this strategy, several exploratory studies investigating combination therapies have been conducted, showing variable but overall favorable clinical response rates in BRAFmt mCRCs [123-125]. Furthermore, the phase III trial BEACON has recently proved a significant survival advantage for the combination of encorafenib plus cetuximab or the same doublet plus binimetinib compared to current standard treatments [126, 127]. This seminal study will pave the way for innovative BRAF-specific therapeutic options.

One of the less explored aspect is the potential predictive value of the different $B R A F$ mutation types. Actually, in vitro assays validated a BM1 cell lines sensitivity to BRAF-, MEK- and BCL2-inhibitor and a BM2 cell lines sensitivity to CDK1 inhibition [70]. In addition, functional in vitro studies conducted on melanoma models showed that FDA-approved BRAF inhibitors vemurafenib and dabrafenib are only effective against class 1 monomer-type mutations (V600 mutations); whereas, class 2 is sensitive to novel panRAF-inhibitor (LY3009120) or MEK-inhibitors (trametininb) and class 3 to EGFR-inhibitor (cetuximab and panitumumab) and RTKs-inhibitors (dasatinib) [34, 71, 128].

Consistent with in-vitro data, BM subtypes and $B R A F$ mutations classes might differ in drug-response even in clinical settings, validating the heterogeneous targetedtherapies response in BRAFmt patients cohort and supporting prospective testing of novel drug combinations in selected patients subsets [70].

\section{Conclusion and future directions}

Although $B R A F$ mutation is a relatively rare finding in $\mathrm{mCRC}$, it is characterized by a critical negative impact in clinical presentation, histology, molecular features, patient outcomes and therapeutic strategies. This is, however, strictly related and dependent on the genetic and epigenetic background that could evolve during disease and therapy, differently from other $B R A F$ mutated malignancies. In fact, $B R A F$ mutation frequency in early staged CRC is probably underestimated and its prognostic value in this setting remains unclear as demonstrated by poor and contradictory data published to date. 
The predictive value of $B R A F$ mutation in mCRCs is still blurred; patients bearing this alteration are likely to not respond to therapeutic schemes based on a single TKI; on the contrary, different combinatorial therapies could have an heterogeneous response pinpointing an inter and intra-tumoral heterogeneity. Although several mechanisms of TKI resistance have been investigated, we are still far from a deep molecular comprehension of BRAFmt CRCs.

More efforts are needed to provide the knowledge for a rational use of targeted and combined therapies, in order to minimize the selective pressure of resistant clones and reduce side effects. So, it could be useful to further classify and stratify the $B R A F$ mutant population, in order to improve the efficacy of personalized therapies.

\section{Acknowledgements}

Not applicable.

\section{Authors' contributions}

All authors of this research paper participated directly in the planning and execution of the study, and in the analysis of the results. GNF, CADP, ID, MS, $S B, P B, M B, L D S, S L, G M, F L$ and MF actively participated in the writing of the article. All authors read and approved the final manuscript.

\section{Funding}

This article was partly supported by the Grant NET-2016-02363853 from the Italian Ministry of Health.

\section{Availability of data and materials}

Not applicable

\section{Ethics approval and consent to participate} Not applicable.

\section{Consent for publication}

Not applicable.

\section{Competing interests}

Fotios Loupakis had roles as a consultant or advisor for Roche, Bayer, Amgen and Genentech Pharmaceuticals. Sara Lonardi had roles as a consultant or advisor for Amgen, Bayer, Merck Serono and Lilly. She received research funding from Amgen and Merck Serono, and she is part of the speakers' bureau of Lilly and BMS. Matteo Fassan had roles as a consultant or advisor for Tesaro and Astellas. He received research funding from Astellas and QED. The other authors have no competing interests to declare. The authors declare that they have no competing interests.

\section{Author details}

${ }^{1}$ Surgical Pathology Unit, Department of Medicine (DIMED), University of Padua, via Gabelli 61, 35121 Padua, Italy. ${ }^{2}$ Department of Oncology, Veneto Institute of Oncology IOV-IRCCS, Padua, Italy.

Received: 6 August 2019 Accepted: 20 January 2020

Published online: 29 January 2020

\section{References}

1. Bray F, Ferlay J, Soerjomataram I, Siegel RL, Torre LA, Jemal A. Global cancer statistics 2018: GLOBOCAN estimates of incidence and mortality worldwide for 36 cancers in 185 countries. CA Cancer J Clin. 2018;68(6):394-424.

2. Vogelstein B, Fearon ER, Hamilton SR, Kern SE, Preisinger AC, Leppert M, Smits AMM, Bos JL. Genetic alterations during colorectal-tumor development. N Engl J Med. 1988;319(9):525-32.
3. Guinney J, Dienstmann R, Wang X, de Reynies A, Schlicker A, Soneson C, Marisa L, Roepman P, Nyamundanda G, Angelino P, et al. The consensus molecular subtypes of colorectal cancer. Nat Med. 2015;21(11):1350-6.

4. Sepulveda AR, Hamilton SR, Allegra CJ, Grody W, Cushman-Vokoun AM, Funkhouser WK, Kopetz SE, Lieu C, Lindor NM, Minsky BD, et al. Molecular biomarkers for the evaluation of colorectal cancer: guideline summary from the american society for clinical pathology, college of american pathologists, association for molecular pathology, and american society of clinical oncology. J Oncol Pract. 2017;13(5):333-7.

5. Morkel M, Riemer P, Blaker H, Sers C. Similar but different: distinct roles for KRAS and BRAF oncogenes in colorectal cancer development and therapy resistance. Oncotarget. 2015;6:25.

6. Kim EK, Choi E-J. Compromised MAPK signaling in human diseases: an update. Arch Toxicol. 2015;89(6):867-82.

7. Sanchez JN, Wang T, Cohen MS. BRAF and MEK inhibitors: use and resistance in BRAF-mutated cancers. Drugs. 2018;78(5):549-66.

8. Galuppini F, Pennelli G, Loupakis F, Lanza C, Vianello L, Sacchi D, Mescoli C, Salmaso R, Agostini M, Lonardi S, et al. BRAF p.V600E-specific immunohistochemical assessment in colorectal cancer endoscopy biopsies is consistent with the mutational profiling. Histopathology. 2017;71(6):1008-11.

9. Yaeger R, Corcoran RB. Targeting Alterations in the RAF, ÄiMEK pathway. Cancer discovery. 2019;9(3):329-41.

10. Yokota T, Ura T, Shibata N, Takahari D, Shitara K, Nomura M, Kondo C, Mizota A, Utsunomiya S, Muro K, et al. BRAF mutation is a powerful prognostic factor in advanced and recurrent colorectal cancer. $\mathrm{Br} J$ Cancer. 2011;104(5):856-62.

11. Wellbrock C, Ogilvie L, Hedley D, Karasarides M, Martin J, NiculescuDuvaz D, Springer CJ, Marais R. V599EB-RAF is an oncogene in melanocytes. Cancer Res. 2004;64(7):2338-42.

12. Long GV, Menzies AM, Nagrial AM, Haydu LE, Hamilton AL, Mann GJ, Hughes TM, Thompson JF, Scolyer RA, Kefford RF. Prognostic and clinicopathologic associations of oncogenic BRAF in metastatic melanoma. J Clin Oncol. 2011;29(10):1239-46.

13. Gkolfinopoulos S, Mountzios G. Beyond EGFR and ALK: targeting rare mutations in advanced non-small cell lung cancer. Ann Transl Med. 2018;6(8):142.

14. Chen D, Huang J-F, Liu K, Zhang L-Q, Yang Z, Chuai Z-R, Wang Y-X, Shi D-C, Huang Q, Fu W-L. BRAFV600E mutation and its association with clinicopathological features of colorectal cancer: a systematic review and meta-analysis. PLoS ONE. 2014;9(3):e90607.

15. Clarke CN, Kopetz ES. BRAF mutant colorectal cancer as a distinct subset of colorectal cancer: clinical characteristics, clinical behavior, and response to targeted therapies. J Gastrointest Oncol. 2015;6(6):660-7.

16. Jang MH, Kim S, Hwang DY, Kim WY, Lim SD, Kim WS, Hwang TS, Han HS. BRAF-mutated colorectal cancer exhibits distinct clinicopathological features from wild-TypeBRAF-expressing cancer independent of the microsatellite instability status. J Kor Med Sci. 2017;32(1):38.

17. Fassan M, Vianello L, Sacchi D, Fanelli GN, Munari G, Scarpa M, Cappellesso R, Loupakis F, Lanza C, Salmaso R, et al. Assessment of intratumor immune-microenvironment in colorectal cancers with extranodal extension of nodal metastases. Cancer Cell Int. 2018;18:131.

18. Fassan M, Vianello L, Sacchi D, Fanelli GN, Munari G, Scarpa M, Cappellesso R, Loupakis F, Lanza C, Salmaso R, et al. Correction to: assessment of intratumor immune-microenvironment in colorectal cancers with extranodal extension of nodal metastases. Cancer Cell Int. 2019;19:244.

19. Ahronian LG, Sennott EM, Van Allen EM, Wagle N, Kwak EL, Faris JE, Godfrey JT, Nishimura K, Lynch KD, Mermel CH, et al. Clinical acquired resistance to RAF inhibitor combinations in BRAF-mutant colorectal cancer through MAPK pathway alterations. Cancer Discov. 2015;5(4):358-67.

20. Cohen R, Cervera P, Svrcek M, Pellat A, Dreyer C, de Gramont A, Andre T. BRAF-mutated colorectal cancer: what is the optimal strategy for treatment? Curr Treat Options Oncol. 2017;18(2):9.

21. Sartore-Bianchi A, Loupakis F, Argiles G, Prager GW. Challenging chemoresistant metastatic colorectal cancer: therapeutic strategies from the clinic and from the laboratory. Ann Oncol. 2016;27(8):1456-66.

22. Tie J, Desai J. Targeting BRAF mutant metastatic colorectal cancer: clinical implications and emerging therapeutic strategies. Target Oncol. 2015;10(2):179-88. 
23. Cremolini C, Di Bartolomeo M, Amatu A, Antoniotti C, Moretto R, Berenato R, Perrone F, Tamborini E, Aprile G, Lonardi S, et al. BRAFcodons 594 and 596 mutations identify a new molecular subtype of metastatic colorectal cancer at favorable prognosis. Ann Oncol. 2015;26(10):2092-7.

24. Loupakis F, Cremolini C, Salvatore L, Masi G, Sensi E, Schirripa M, Michelucci A, Pfanner E, Brunetti I, Lupi C, et al. FOLFOXIRI plus bevacizumab as first-line treatment in BRAF mutant metastatic colorectal cancer. Eur J Cancer. 2014;50(1):57-63.

25. Roth AD, Tejpar S, Delorenzi M, Yan P, Fiocca R, Klingbiel D, Dietrich D, Biesmans B, Bodoky G, Barone C, et al. Prognostic role of KRAS and BRAF in stage II and III resected colon cancer: results of the translational study on the PETACC-3, EORTC 40993, SAKK 60-00 Trial. J Clin Oncol. 2010;28(3):466-74.

26. Samowitz WS, Sweeney C, Herrick J, Albertsen H, Levin TR, Murtaugh MA, Wolff RK, Slattery ML. Poor survival associated with the BRAF V600E mutation in microsatellite-stable colon cancers. Cancer Res. 2005;65(14):6063-9.

27. Tran B, Kopetz S, Tie J, Gibbs P, Jiang Z-Q, Lieu CH, Agarwal A, Maru DM, Sieber O, Desai J. Impact of BRAF mutation and microsatellite instability on the pattern of metastatic spread and prognosis in metastatic colorectal cancer. Cancer. 2011;117(20):4623-32.

28. Lochhead P, Kuchiba A, Imamura Y, Liao X, Yamauchi M, Nishihara R, Qian ZR, Morikawa T, Shen J, Meyerhardt JA, et al. Microsatellite instability and BRAF mutation testing in colorectal cancer prognostication. J Natl Cancer Inst. 2013;105(15):1151-6.

29. East JE, Atkin WS, Bateman AC, Clark SK, Dolwani S, Ket SN, Leedham SJ, Phull PS, Rutter MD, Shepherd NA, et al. British society of gastroenterology position statement on serrated polyps in the colon and rectum. Gut. 2017;66(7):1181-96.

30. Landau MS, Kuan SF, Chiosea S, Pai RK. BRAF-mutated microsatellite stable colorectal carcinoma: an aggressive adenocarcinoma with reduced CDX2 and increased cytokeratin 7 immunohistochemical expression. Hum Pathol. 2014;45(8):1704-12.

31. Pai RK, Jayachandran P, Koong AC, Chang DT, Kwok S, Ma L, Arber DA, Balise RR, Tubbs RR, Shadrach B, et al. BRAF-mutated, microsatellitestable adenocarcinoma of the proximal colon: an aggressive adenocarcinoma with poor survival, mucinous differentiation, and adverse morphologic features. Am J Surg Pathol. 2012;36(5):744-52.

32. Markowitz SD, Bertagnolli MM. Molecular origins of cancer: molecular basis of colorectal cancer. N Engl J Med. 2009;361(25):2449-60.

33. Seligmann JF, Fisher D, Smith CG, Richman SD, Elliott F, Brown S, Adams R, Maughan T, Quirke P, Cheadle J, et al. Investigating the poor outcomes of BRAF - mutant advanced colorectal cancer: analysis from 2530 patients in randomised clinical trials. Ann Oncol. 2016;28:mdw645.

34. Schirripa M, Biason P, Lonardi S, Pella N, Pino MS, Urbano F, Antoniotti C, Cremolini C, Corallo S, Pietrantonio F, et al. Class 1, 2, and 3 BRAFmutated metastatic colorectal cancer: a detailed clinical, pathologic, and molecular characterization. Clin Cancer Res. 2019;25(13):3954-61.

35. Barras D. BRAF mutation in colorectal cancer: an update. Biomark Cancer. 2015;7s1:BIC.S25248

36. Wan PT, Garnett MJ, Roe SM, Lee S, Niculescu-Duvaz D, Good VM, Jones CM, Marshall CJ, Springer CJ, Barford D, et al. Mechanism of activation of the RAF-ERK signaling pathway by oncogenic mutations of B-RAF. Cell. 2004;1 16(6):855-67.

37. Davies H, Bignell GR, Cox C, Stephens P, Edkins S, Clegg S, Teague J, Woffendin $\mathrm{H}$, Garnett MJ, Bottomley W, et al. Mutations of the BRAF gene in human cancer. Nature. 2002;417(6892):949-54.

38. Strickler JH, Wu C, Bekaii-Saab T. Targeting BRAF in metastatic colorectal cancer: maximizing molecular approaches. Cancer Treat Rev. 2017;60:109-19.

39. Kim JH, Kang GH. Molecular and prognostic heterogeneity of microsatellite-unstable colorectal cancer. World J Gastroenterol. 2014;20(15):4230-43.

40. Birgisson H, Edlund K, Wallin U, Pahlman L, Kultima HG, Mayrhofer M, Micke P, Isaksson A, Botling J, Glimelius B, et al. Microsatellite instability and mutations in BRAF and KRAS are significant predictors of disseminated disease in colon cancer. BMC Cancer. 2015;15:125.

41. Farina-Sarasqueta A, van Lijnschoten G, Moerland E, Creemers GJ, Lemmens VE, Rutten HJ, van den Brule AJ. The BRAF V600E mutation is an independent prognostic factor for survival in stage II and stage III colon cancer patients. Ann Oncol. 2010;21(12):2396-402.

42. Clancy C, Burke JP, Kalady MF, Coffey JC. BRAFmutation is associated with distinct clinicopathological characteristics in colorectal cancer: a systematic review and meta-analysis. Colorect Dis. 2013;15(12):e711-8.

43. Roma C, Rachiglio AM, Pasquale R, Fenizia F, lannaccone A, Tatangelo F, Antinolfi G, Parrella P, Graziano P, Sabatino L, et al. BRAF V600E mutation in metastatic colorectal cancer: methods of detection and correlation with clinical and pathologic features. Cancer Biol Ther. 2016;17(8):840-8.

44. Loupakis F, Moretto R, Aprile G, Muntoni M, Cremolini C, lacono D, Casagrande M, Ferrari L, Salvatore L, Schirripa M, et al. Clinico-pathological nomogram for predicting BRAF mutational status of metastatic colorectal cancer. Br J Cancer. 2015;114(1):30-6.

45. Schirripa M, Cremolini C, Loupakis F, Morvillo M, Bergamo F, Zoratto F, Salvatore L, Antoniotti C, Marmorino F, Sensi E, et al. Role ofNRASmutations as prognostic and predictive markers in metastatic colorectal cancer. Int J Cancer. 2014;136(1):83-90.

46. Kayhanian H, Goode E, Sclafani F, Ang JE, Gerlinger M, Gonzalez de Castro D, Shepherd S, Peckitt C, Rao S, Watkins D, et al. Treatment and survival outcome of BRAF-mutated metastatic colorectal cancer: a retrospective matched case-control study. Clin Colorect Cancer. 2018;17(1):69-76.

47. Cappell MS. From colonic polyps to colon cancer: pathophysiology, clinical presentation, and diagnosis. Clin Lab Med. 2005;25(1):135-77.

48. Higuchi T, Jass JR. My approach to serrated polyps of the colorectum. J Clin Pathol. 2004;57(7):682-6.

49. Walther A, Johnstone E, Swanton C, Midgley R, Tomlinson I, Kerr D. Genetic prognostic and predictive markers in colorectal cancer. Nat Rev Cancer. 2009:9(7):489-99.

50. Tie J, Gibbs P, Lipton L, Christie M, Jorissen RN, Burgess AW, Croxford M, Jones I, Langland R, Kosmider S, et al. Optimizing targeted therapeutic development: analysis of a colorectal cancer patient population with the BRAFV600E mutation. Int J Cancer. 2010;128(9):2075-84.

51. Pai RK, Bettington M, Srivastava A, Rosty C. An update on the morphology and molecular pathology of serrated colorectal polyps and associated carcinomas. Mod Pathol. 2019:32(10):1390-415.

52. De Maio G, Zama E, Rengucci C, Calistri D. What influences preneoplastic colorectal lesion recurrence? Oncotarget. 2017;8(7):12406-16.

53. Michalopoulos G, Tzathas C. Serrated polyps of right colon: guilty or innocent? Ann Gastroenterol. 2013;26(3):212-9.

54. Yang H-M, Mitchell JM, Sepulveda JL, Sepulveda AR. Molecular and histologic considerations in the assessment of serrated polyps. Arch Pathol Lab Med. 2015;139(6):730-41.

55. Szylberg L, Janiczek M, Popiel A, Marszalek A. Serrated polyps and their alternative pathway to the colorectal cancer: a systematic review. Gastroenterol Res Pract. 2015:2015:573814.

56. Vu HT, Lopez R, Bennett A, Burke CA. Individuals with sessile serrated polyps express an aggressive colorectal phenotype. Dis Colon Rect. 2011;54(10):1216-23.

57. Schreiner MA, Weiss DG, Lieberman DA. Proximal and large hyperplastic and nondysplastic serrated polyps detected by colonoscopy are associated with neoplasia. Gastroenterology. 2010;139(5):1497-502.

58. Lu F-I, van Niekerk DW, Owen D, Tha SPL, Turbin DA, Webber DL. Longitudinal outcome study of sessile serrated adenomas of the colorectum: an increased risk for subsequent right-sided colorectal carcinoma. Am J Surg Pathol. 2010;34(7):927-34.

59. Liu C, Walker NI, Leggett BA, Whitehall VL, Bettington ML, Rosty C. Sessile serrated adenomas with dysplasia: morphological patterns and correlations with MLH1 immunohistochemistry. Mod Pathol. 2017;30(12):1728-38.

60. Nosho K, Igarashi H, Ito M, Mitsuhashi K, Kurihara H, Kanno S, Yoshii S, Mikami M, Takahashi H, Kusumi T, et al. Clinicopathological and molecular characteristics of serrated lesions in Japanese elderly patients. Digestion. 2015;91(1):57-63.

61. Kalimuthu SN, Chelliah A, Chetty R. From traditional serrated adenoma to tubulovillous adenoma and beyond. World J Gastrointest Oncol. 2016;8(12):805.

62. Cappellesso R, Lo Mele M, Munari G, Rosa-Rizzotto E, Guido E, De Lazzari F, Pilati P, Tonello M, Farinati F, Realdon S, et al. Molecular characterization of "sessile serrated" adenoma to carcinoma transition in six early colorectal cancers. Pathol Res Pract. 2019;215(5):957-62. 
63. Rosenberg DW, Yang S, Pleau DC, Greenspan EJ, Stevens RG, Rajan TV, Heinen CD, Levine J, Zhou Y, O'Brien MJ. Mutations in BRAF and KRAS differentially distinguish serrated versus non-serrated hyperplastic aberrant crypt foci in humans. Cancer Res. 2007;67(8):3551-4.

64. Artale S, Sartore-Bianchi A, Veronese SM, Gambi V, Sarnataro CS, Gambacorta M, Lauricella C, Siena S. Mutations ofKRASandBRAFin primary and matched metastatic sites of colorectal cancer. J Clin Oncol. 2008;26(25):4217-9.

65. Lannagan TRM, Lee YK, Wang T, Roper J, Bettington ML, Fennell L, Vrbanac L, Jonavicius L, Somashekar R, Gieniec K, et al. Genetic editing of colonic organoids provides a molecularly distinct and orthotopic preclinical model of serrated carcinogenesis. Gut. 2019;68(4):684-92.

66. Rad R, Cadianos J, Rad L, Varela I, Strong A, Kriegl L, Constantino-Casas F, Eser S, Hieber M, Seidler B, et al. A genetic progression model of BrafV600E-induced intestinal tumorigenesis reveals targets for therapeutic intervention. Cancer Cell. 2013;24(1):15-29.

67. Fang M, Ou J, Hutchinson L, Green MR. The BRAF oncoprotein functions through the transcriptional repressor MAFG to mediate the CpG Island Methylator phenotype. Mol Cell. 2014;55(6):904-15.

68. Kambara T. BRAF mutation is associated with DNA methylation in serrated polyps and cancers of the colorectum. Gut. 2004;53(8):1137-44.

69. Loupakis F, Biason P, Prete AA, Cremolini C, Pietrantonio F, Pella N, Dell'Aquila E, Sperti E, Zichi C, Intini R, et al. CK7 and consensus molecular subtypes as major prognosticators in (V600E)BRAF mutated metastatic colorectal cancer. Br J Cancer. 2019;121(7):593-9.

70. Barras D, Missiaglia E, Wirapati P, Sieber OM, Jorissen RN, Love C, Molloy PL, Jones IT, McLaughlin S, Gibbs P, et al. BRAF V600E mutant colorectal cancer subtypes based on gene expression. Clin Cancer Res. 2017;23(1):104-15.

71. Yao Z, Torres NM, Tao A, Gao Y, Luo L, Li Q, de Stanchina E, Abdel-Wahab $\mathrm{O}$, Solit DB, Poulikakos PI, et al. BRAF mutants evade ERK-dependent feedback by different mechanisms that determine their sensitivity to pharmacologic inhibition. Cancer Cell. 2015;28(3):370-83.

72. Yao Z, Yaeger R, Rodrik-Outmezguine VS, Tao A, Torres NM, Chang MT, Drosten M, Zhao H, Cecchi F, Hembrough T, et al. Tumours with class 3 BRAF mutants are sensitive to the inhibition of activated RAS. Nature. 2017;548(7666):234-8.

73. Heidorn SJ, Milagre C, Whittaker S, Nourry A, Niculescu-Duvas I, Dhomen N, Hussain J, Reis-Filho JS, Springer CJ, Pritchard C, et al. Kinase-dead BRAF and oncogenic RAS cooperate to drive tumor progression through CRAF. Cell. 2010;140(2):209-21.

74. Jones JC, Renfro LA, Al-Shamsi HO, Schrock AB, Rankin A, Zhang BY, Kasi PM, Voss JS, Leal AD, Sun J, et al. (Non-V600) BRAF mutations define a clinically distinct molecular subtype of metastatic colorectal cancer. $J$ Clin Oncol. 2017;35(23):2624-30.

75. Luchini C, Bibeau F, Ligtenberg MJL, Singh N, Nottegar A, Bosse T, Miller R, Riaz N, Douillard JY, Andre F, et al. ESMO recommendations on microsatellite instability testing for immunotherapy in cancer, and its relationship with PD-1/PD-L1 expression and tumour mutational burden: a systematic review-based approach. Ann Oncol. 2019;30(8):1232-43.

76. Loughrey MB, Waring PM, Tan A, Trivett M, Kovalenko S, Beshay V, Young MA, McArthur G, Boussioutas A, Dobrovic A. Incorporation of somatic BRAF mutation testing into an algorithm for the investigation of hereditary non-polyposis colorectal cancer. Fam Cancer. 2007;6(3):301-10.

77. Chong LC, Townsend AR, Young J, Roy A, Piantadosi C, Hardingham JE, Roder D, Karapetis C, Padbury R, Maddern G, et al. Outcomes for metastatic colorectal cancer based on microsatellite instability: results from the south australian metastatic colorectal cancer registry. Target Oncol. 2019;14(1):85-91.

78. Kawakami H, Zaanan A, Sinicrope FA. Implications of mismatch repairdeficient status on management of early stage colorectal cancer. J Gastrointest Oncol. 2015;6(6):676-84.

79. Kawakami H, Zaanan A, Sinicrope FA. Microsatellite instability testing and its role in the management of colorectal cancer. Curr Treat Options Oncol. 2015;16(7):30.

80. Weisenberger DJ, Siegmund KD, Campan M, Young J, Long TI, Faasse MA, Kang GH, Widschwendter M, Weener D, Buchanan D, et al. CpG island methylator phenotype underlies sporadic microsatellite instability and is tightly associated with BRAF mutation in colorectal cancer. Nat Genet. 2006;38(7):787-93.
81. Parsons MT, Buchanan DD, Thompson B, Young JP, Spurdle AB. Correlation of tumour BRAF mutations and MLH1 methylation with germline mismatch repair (MMR) gene mutation status: a literature review assessing utility of tumour features for MMR variant classification. J Med Genet. 2012:49(3):151-7.

82. Bond CE, Nancarrow DJ, Wockner LF, Wallace L, Montgomery GW, Leggett BA, Whitehall VL. Microsatellite stable colorectal cancers stratified by the BRAF V600E mutation show distinct patterns of chromosomal instability. PLoS ONE. 2014;9(3):e91739.

83. Bond CE, Umapathy A, Buttenshaw RL, Wockner L, Leggett BA, Whitehall VL. Chromosomal instability in BRAF mutant, microsatellite stable colorectal cancers. PLoS One. 2012;7(10):e47483.

84. Bond CE, Umapathy A, Ramsnes I, Greco SA, Zhen Zhao Z, Mallitt KA, Buttenshaw RL, Montgomery GW, Leggett BA, Whitehall VL. p53 mutation is common in microsatellite stable, BRAF mutant colorectal cancers. Int J Cancer. 2012;130(7):1567-76.

85. Rajagopalan H, Bardelli A, Lengauer C, Kinzler KW, Vogelstein B, Velculescu VE. RAF/RAS oncogenes and mismatch-repair status. Nature. 2002;418(6901):934.

86. Fransen K, Klintenas M, Osterstrom A, Dimberg J, Monstein HJ, Soderkvist P. Mutation analysis of the BRAF, ARAF and RAF-1 genes in human colorectal adenocarcinomas. Carcinogenesis. 2004;25(4):527-33.

87. Gatalica Z, Torlakovic E. Pathology of the hereditary colorectal carcinoma. Familial Cancer. 2007;7(1):15-26.

88. Jenkins MA, Hayashi S, O'Shea AM, Burgart L, Smyrk TC, Shimizu D, Waring PM, Ruszkiewicz AR, Pollett AF, Redston M, et al. Pathology features in Bethesda guidelines predict colorectal cancer microsatellite instability: a population-based study. Gastroenterology. 2007;133(1):48-56.

89. Zlobec I, Bihl MP, Schwarb H, Terracciano L, Lugli A. Clinicopathological and protein characterization ofBRAF- andK-RAS-mutated colorectal cancer and implications for prognosis. Int J Cancer. 2010;127(2):367-80.

90. Kim JH, Rhee YY, Bae JM, Cho NY, Kang GH. Loss of CDX2/CK20 expression is associated with poorly differentiated carcinoma, the CpG island methylator phenotype, and adverse prognosis in microsatellite-unstable colorectal cancer. Am J Surg Pathol. 2013;37(10):1532-41.

91. Zlobec I, Bihl M, Foerster A, Rufle A, Lugli A. Comprehensive analysis of CpG island methylator phenotype (CIMP)-high,-low, and -negative colorectal cancers based on protein marker expression and molecular features. J Pathol. 2011;225(3):336-43.

92. Lugli A, Tzankov A, Zlobec I, Terracciano LM. Differential diagnostic and functional role of the multi-marker phenotype CDX2/CK20/CK7 in colorectal cancer stratified by mismatch repair status. Mod Pathol. 2008;21(11):1403-12.

93. Harbaum L, Pollheimer MJ, Kornprat P, Lindtner RA, Schlemmer A, Rehak P, Langner C. Keratin 7 expression in colorectal cancer-freak of nature or significant finding? Histopathology. 2011;59(2):225-34.

94. Sinicrope FA, Shi Q, Smyrk TC, Thibodeau SN, Dienstmann R, Guinney J, Bot BM, Tejpar S, Delorenzi M, Goldberg RM, et al. Molecular markers identify subtypes of stage III colon cancer associated with patient outcomes. Gastroenterology. 2015;148(1):88-99.

95. Tosi F, Magni E, Amatu A, Mauri G, Bencardino K, Truini M, Veronese S, De Carlis L, Ferrari G, Nichelatti M, et al. Effect of KRAS and BRAF mutations on survival of metastatic colorectal cancer after liver resection: a systematic review and meta-analysis. Clin Colorect Cancer. 2017;16(3):e153-63.

96. Jass JR, Do KA, Simms LA, lino H, Wynter C, Pillay SP, Searle J, RadfordSmith G, Young J, Leggett B. Morphology of sporadic colorectal cancer with DNA replication errors. Gut. 1998;42(5):673-9.

97. Ogino S, Nosho K, Kirkner GJ, Kawasaki T, Meyerhardt JA, Loda M, Giovannucci EL, Fuchs CS. CpG island methylator phenotype, microsatellite instability, BRAF mutation and clinical outcome in colon cancer. Gut. 2008;58(1):90-6.

98. Franko J, Shi Q, Meyers JP, Maughan TS, Adams RA, Seymour MT, Saltz L, Punt CJA, Koopman M, Tournigand C, et al. Prognosis of patients with peritoneal metastatic colorectal cancer given systemic therapy: an analysis of individual patient data from prospective randomised trials from the Analysis and Research in Cancers of the Digestive System (ARCAD) database. Lancet Oncol. 2016;17(12):1709-19.

99. Intini R, Loupakis F, Cremolini C, Sartore-Bianchi A, Pietrantonio F, Pella N, Santini D, Rimassa L, Formica V, Calvetti L, et al. Clinical 
prognostic score of BRAF V600E mutated (BM) metastatic colorectal cancer (mCRC): results from the "BRAF, BeCool" platform. J Clin Oncol. 2018;36_Suppl(4):639.

100. Loupakis F, Intini R, Cremolini C, Orlandi A, Sartore-Bianchi A, Pietrantonio F, Pella N, Spallanzani A, Dell'Aquila E, Scartozzi M, et al. A validated prognostic classifier for (V600E)BRAF-mutated metastatic colorectal cancer: the 'BRAF BeCool'study. Eur J Cancer. 2019;118:121-30.

101. Tol J, Nagtegaal ID, Punt CJ. BRAF mutation in metastatic colorectal cancer. N Engl J Med. 2009;361(1):98-9.

102. Souglakos J, Philips J, Wang R, Marwah S, Silver M, Tzardi M, Silver J, Ogino S, Hooshmand S, Kwak E, et al. Prognostic and predictive value of common mutations for treatment response and survival in patients with metastatic colorectal cancer. Br J Cancer. 2009;101 (3):465-72.

103. Karapetis CS, Khambata-Ford S, Jonker DJ, O'Callaghan CJ, Tu D, Tebbutt NC, Simes RJ, Chalchal H, Shapiro JD, Robitaille S, et al. K-ras mutations and benefit from cetuximab in advanced colorectal cancer. N Engl J Med. 2008;359(17):1757-65.

104. Lievre A, Bachet JB, Le Corre D, Boige V, Landi B, Emile JF, Cote JF, Tomasic G, Penna C, Ducreux M, et al. KRAS mutation status is predictive of response to cetuximab therapy in colorectal cancer. Cancer Res. 2006;66(8):3992-5.

105. Van Cutsem E, Kohne CH, Hitre E, Zaluski J, Chang Chien CR, Makhson A, D'Haens G, Pinter T, Lim R, Bodoky G, et al. Cetuximab and chemotherapy as initial treatment for metastatic colorectal cancer. N Engl J Med. 2009;360(14):1408-17.

106. De Roock W, Claes B, Bernasconi D, De Schutter J, Biesmans B, Fountzilas G, Kalogeras KT, Kotoula V, Papamichael D, Laurent-Puig P, et al. Effects of KRAS, BRAF, NRAS, and PIK3CA mutations on the efficacy of cetuximab plus chemotherapy in chemotherapy-refractory metastatic colorectal cancer: a retrospective consortium analysis. Lancet Oncol. 2010:11(8):753-62.

107. Douillard JY, Oliner KS, Siena S, Tabernero J, Burkes R, Barugel M, Humblet Y, Bodoky G, Cunningham D, Jassem J, et al. PanitumumabFOLFOX4 treatment and RAS mutations in colorectal cancer. N Engl J Med. 2013;369(11):1023-34.

108. Di Nicolantonio F, Martini M, Molinari F, Sartore-Bianchi A, Arena S, Saletti P, De Dosso S, Mazzucchelli L, Frattini M, Siena S, et al. WildTypeBRAFIs required for response to panitumumab or cetuximab in metastatic colorectal cancer. J Clin Oncol. 2008;26(35):5705-12.

109. Loupakis F, Ruzzo A, Cremolini C, Vincenzi B, Salvatore L, Santini D, Masi G, Stasi I, Canestrari E, Rulli E, et al. KRAS codon 61, 146 and BRAF mutations predict resistance to cetuximab plus irinotecan in KRAS codon 12 and 13 wild-type metastatic colorectal cancer. Br J Cancer. 2009;101(4):715-21.

110. Pietrantonio F, Petrelli F, Coinu A, Di Bartolomeo M, Borgonovo K, Maggi C, Cabiddu M, lacovelli R, Bossi I, Lonati V, et al. Predictive role of BRAF mutations in patients with advanced colorectal cancer receiving cetuximab and panitumumab: a meta-analysis. Eur J Cancer. 2015;51(5):587-94.

111. Rowland A, Dias MM, Wiese MD, Kichenadasse G, McKinnon RA, Karapetis CS, Sorich MJ. Meta-analysis of BRAF mutation as a predictive biomarker of benefit from anti-EGFR monoclonal antibody therapy for RAS wild-type metastatic colorectal cancer. Br J Cancer. 2015;112(12):1888-94.

112. Falcone A, Ricci S, Brunetti I, Pfanner E, Allegrini G, Barbara C, Crino L, Benedetti G, Evangelista W, Fanchini L, et al. Phase III trial of infusional fluorouracil, leucovorin, oxaliplatin, and irinotecan (FOLFOXIRI) compared with infusional fluorouracil, leucovorin, and irinotecan (FOLFIRI) as first-line treatment for metastatic colorectal cancer: the Gruppo Oncologico Nord Ovest. J Clin Oncol. 2007;25(13):1670-6.

113. Loupakis F, Cremolini C, Masi G, Lonardi S, Zagonel V, Salvatore L, Cortesi E, Tomasello G, Ronzoni M, Spadi R, et al. Initial therapy with FOLFOXIRI and bevacizumab for metastatic colorectal cancer. N Engl J Med. 2014;371(17):1609-18.

114. Masi G, Loupakis F, Salvatore L, Fornaro L, Cremolini C, Cupini S, Ciarlo A, Del Monte F, Cortesi E, Amoroso D, et al. Bevacizumab with FOLFOXIRI (irinotecan, oxaliplatin, fluorouracil, and folinate) as first-line treatment for metastatic colorectal cancer: a phase 2 trial. Lancet Oncol. 2010;11(9):845-52.

115. Cremolini C, Loupakis F, Antoniotti C, Lupi C, Sensi E, Lonardi S, Mezi S, Tomasello G, Ronzoni M, Zaniboni A, et al. FOLFOXIRI plus bevacizumab versus FOLFIRI plus bevacizumab as first-line treatment of patients with metastatic colorectal cancer: updated overall survival and molecular subgroup analyses of the open-label, phase 3 TRIBE study. Lancet Oncol. 2015;16(13):1306-15.

116. Cremolini C, Loupakis F, Masi G, Lonardi S, Granetto C, Mancini ML, Chiara S, Moretto R, Rossini D, Vitello S, et al. FOLFOXIRI or FOLFOXIRI plus bevacizumab as first-line treatment of metastatic colorectal cancer: a propensity score-adjusted analysis from two randomized clinical trials. Ann Oncol. 2016;27(5):843-9.

117. Mandala M, Voit C. Targeting BRAF in melanoma: biological and clinical challenges. Crit Rev Oncol Hematol. 2013;87(3):239-55.

118. Chapman PB, Hauschild A, Robert C, Haanen JB, Ascierto P, Larkin J, Dummer R, Garbe C, Testori A, Maio M, et al. Improved survival with vemurafenib in melanoma with BRAF V600E mutation. N Engl J Med. 2011;364(26):2507-16.

119. Prahallad A, Sun C, Huang S, Di Nicolantonio F, Salazar R, Zecchin D, Beijersbergen RL, Bardelli A, Bernards R. Unresponsiveness of colon cancer to $\operatorname{BRAF}(\mathrm{V} 600 \mathrm{E})$ inhibition through feedback activation of EGFR. Nature. 2012;483(7387):100-3.

120. Corcoran RB, Ebi H, Turke AB, Coffee EM, Nishino M, Cogdill AP, Brown RD, Della Pelle P, Dias-Santagata D, Hung KE, et al. EGFR-mediated re-activation of MAPK signaling contributes to insensitivity of BRAF mutant colorectal cancers to RAF inhibition with vemurafenib. Cancer Discov. 2012;2(3):227-35.

121. Little AS, Balmanno K, Sale MJ, Newman S, Dry JR, Hampson M, Edwards PA, Smith PD, Cook SJ. Amplification of the driving oncogene, KRAS or BRAF, underpins acquired resistance to MEK $1 / 2$ inhibitors in colorectal cancer cells. Sci Signal. 2011;4(166):ra17.

122. Ahmed D, Eide PW, Eilertsen IA, Danielsen SA, Eknaes M, Hektoen M, Lind GE, Lothe RA. Epigenetic and genetic features of 24 colon cancer cell lines. Oncogenesis. 2013;2:e71.

123. Hong DS, Morris VK, Fu S, Overman MJ, Piha-Paul SA, Kee BK, Zinner R, Fogelman DR, Mistry R, Shureiqi I, et al. Phase 1B study of vemurafenib in combination with irinotecan and cetuximab in patients with BRAFmutated advanced cancers and metastatic colorectal cancer. J Clin Oncol. 2014;32_Suppl(15):3516.

124. Corcoran RB, Andre T, Atreya CE, Schellens JHM, Yoshino T, Bendell JC, Hollebecque A, McRee AJ, Siena S, Middleton G, et al. Combined BRAF, EGFR, and MEK inhibition in patients with BRAF(V600E)-mutant colorectal cancer. Cancer Discov. 2018;8(4):428-43.

125. Sullivan RJ, Infante JR, Janku F, Wong DJL, Sosman JA, Keedy V, Patel MR, Shapiro Gl, Mier JW, Tolcher AW, et al. First-in-Class ERK1/2 inhibitor ulixertinib (BVD-523) in patients with MAPK mutant advanced solid tumors: results of a phase I dose-escalation and expansion study. Cancer Discov. 2018;8(2):184-95.

126. Van Cutsem E, Huijberts S, Grothey A, Yaeger R, Cuyle PJ, Elez E, Fakih M, Montagut C, Peeters M, Yoshino T, et al. Binimetinib, encorafenib, and cetuximab triplet therapy for patients with BRAF V600E-mutant metastatic colorectal cancer: safety lead-in results from the phase III BEACON colorectal cancer study. J Clin Oncol. 2019;37(17):1460-9.

127. Kopetz S, Grothey A, Yaeger R, Van Cutsem E, Desai J, Yoshino T, Wasan $H$, Ciardiello F, Loupakis F, Hong YS, et al. Encorafenib, binimetinib, and cetuximab in BRAF V600E-mutated colorectal cancer. N Engl J Med. 2019;381(17):1632-43.

128. Misale S, Arena S, Lamba S, Siravegna G, Lallo A, Hobor S, Russo M, Buscarino M, Lazzari L, Sartore-Bianchi A, et al. Blockade of EGFR and MEK intercepts heterogeneous mechanisms of acquired resistance to antiEGFR therapies in colorectal cancer. Sci Transl Med. 2014;6(224):ra226.

\section{Publisher's Note}

Springer Nature remains neutral with regard to jurisdictional claims in published maps and institutional affiliations. 